\title{
Formação ou produção de professores/as para a educação de jovens e adultos?
}

\section{Paula Cabral ${ }^{1}$ e Samira de Moraes Maia Vigano ${ }^{2}$}

1 Doutoranda no Programa de Pós-graduação em Educação da Universidade Federal de Santa Catarina. Bolsista UNIEDU/FUMDES/SC. Orientadora Pedagógica do Programa Institucional de Apoio Pedagógico aos Estudantes - PIAPE/UFSC, Brasil. E-mail: paulica15@hotmail.com

2 Doutoranda no Programa de Pós-graduação em Educação da Universidade Federal de Santa Catarina. Bolsista UNIEDU/FUMDES/SC. Orientadora Pedagógica do Programa Institucional de Apoio Pedagógico aos Estudantes - PIAPE/UFSC, Brasil. E-mail: samirammvigano@gmail.com

RESUMO: As discussões no campo da formação de professores/as têm apontado para a necessidade de rupturas com modelos prescritivos, isso requer pensar o processo formativo a partir de uma outra concepção. Desse modo, este artigo busca debater aspectos referentes à formação de professores/as, a fim de problematizar se esta ocorre levando em consideração as especificidades de cada modalidade e dos sujeitos que lá estão, ou se acaba por ser uma produção em massa de profissionais que atendam várias modalidades de educação, sem percepção das singularidades de cada uma delas. Objetiva-se pensar como o binômio experiência e transformação pode contribuir para a reflexão sobre outras possibilidades de formação, ou de produção dos/as professores/as para a Educação de Jovens e Adultos (EJA). Ampara-se teoricamente em Arroyo, Benjamim, Haddad, Larrosa e Nóvoa. Percebe-se que a produção de professores/as precisa ter como referencial um mundo ambivalente, cuja proposição de normatividades para a contingência parta de quem vive. Para tanto, exige-se rever no próprio processo educativo, as relações que se tecem com elementos como o tempo, espaço, corpo, linguagem, técnica, entre outros.

Palavras-Chave: Formação; Produção; Professores/as; Educação de Jovens e Adultos.

Training or production of teachers for education of youth and adults

ABSTRACT: The discussions in the search field of teacher training have pointed to the need for breaks with prescriptive models, but that requires think about training from other conceptions. This article seeks to discuss aspects related with teacher training to problematize whether this formation occurs taking into account the specificities of each modality and of the subjects that are there, or if it turns out to be a mass production of professionals who attend various modalities of education, without perception the singularities of each one of them. The objective is to think how the binomial experience and transformation contributes to the reflection about other possibilities of formation, or production of the teachers for the Education of Young and Adults (EJA). The theoretical basis are researchers as Arroyo, Benjamim, Haddad, Larrosa and Nóvoa. It is possible to perceive that the production of teachers has to have as reference an ambivalent world, whose proposition of norms for the contingency departs from those who live. For this, it is necessary to review in the educational process itself the relationships that build with elements such as time, space, body, language, technique, among others.

Keywords: Training; Production; Teachers; Education of Youth And Adults

\section{CONTEXTO INICIAL}

Este artigo busca debater aspectos refe- rentes à formação de professores/as, de modo a problematizar se essa formação ocorre levando em consideração as especi- 
ficidades de cada modalidade e dos sujeitos, ou se acaba por ser uma formação em massa de profissionais que atendam várias modalidades de educação, sem percepção das singularidades de cada uma delas.

As discussões no campo da formação de professores/as têm apontado para a necessidade de rupturas com modelos prescritivos, o que requer pensar uma formação a partir de uma outra concepção "que situe o desenvolvimento pessoal e profissional dos professores/as ao longo dos diferentes ciclos da sua vida". (NÓVOA, 1999, p. 09). Portanto, faz-se necessário encontrar dinâmicas formativas que valorizem a sistematização dos saberes próprios, assim como, a capacidade de transformar a experiência em conhecimento para formalização de um saber profissional de referência.

Nessa perspectiva, pretende-se pensar como o binômio experiência e transformação pode nos ajudar a refletir sobre outras possibilidades de formação, ou de produção, dos/as professores/as para uma modalidade específica da Educação Básica - a Educação de Jovens e Adultos (EJA).

Ao se buscar o campo da EJA como base para os estudos compreende-se que essa modalidade possui especificidades distintas das demais e, por esse motivo, deve ter uma formação própria para os professores/as que nela atuam. Desse modo, no decorrer dessa reflexão serão levantados pontos que possam contribuir para pensar sobre tal processo formativo. Para tanto, este artigo se organiza em três eixos: o primeiro analisará a formação de professores/as para a EJA, contextualizando os elementos políticos e legais; o segundo é um diálogo entre a educação, formação e a produção de professores/as; e, por último, um exercício reflexivo a partir de considerações sobre a experiência e transformação na formação ou produção da docência na EJA.

\section{A FORMAÇÃO DE PROFESSORES/AS PA- RA A EJA: elementos políticos e legais}

A trajetória da EJA é fortemente marcada pela sua marginalização por parte do Estado, pelos jogos de interesse e ao mesmo tempo por lutas vinculadas aos movimentos sociais que geram disputas ou correlações de forças no âmbito das políticas públicas educacionais, como demonstram os estudos de Haddad (1987, 2002), Haddad e Di Pierro (2000), Benite et al. (2010), Sartori (2010; 2011), entre outros.

A formação de professores/as para atuação nessa modalidade da Educação Básica também se caracteriza por essa dinâmica, mediante a imposição de modelos formativos pautados pela lógica da escolarização do ensino regular da idade obrigatória, mas que encontra mecanismos de resistência a tais determinações. Tais contradições podem ser melhor compreendidas diante da fecunda história da EJA, como salienta Arroyo $(2005$, p. 30-31):

Um olhar apressado sobre essa história tende a ver apenas na EJA um campo indefinido, descoberto ou aberto a todo tipo de propostas, de intervenções as mais desencontradas [...]. Porém, essa leitura é parcial apesar de ter sido a que se impôs no imaginário da formulação de políticas, da didática, da organização escolar e até do recontar de nossa história da educação. A EJA sempre aparece vinculada a um outro projeto de sociedade, um projeto de inclusão do povo. Foi sempre um dos campos da educação mais politizados, [...] não fechado e nem burocratizado, por ser um campo de possíveis inter- 
venções de agentes diversos da sociedade.

No movimento político brasileiro, dos anos 1990, diante das mobilizações de educadores e dos movimentos sociais no contexto da abertura política do país, a promulgação da Lei de Diretrizes e Bases da Educação Nacional (LDBEN 9394/96) se configura como um marco importante na formação de professores/as para a EJA. Sua importância tem relação com o reconhecimento da EJA enquanto modalidade educacional, a partir de demandas diversas dos sujeitos que a buscam.

Ainda diante das orientações sobre a formação docente no âmbito das políticas públicas educacionais, em 2002, são instituídas as Diretrizes Curriculares Nacionais para a Formação dos Professores/as da Educação Básica, que visam promover uma identidade aos cursos de licenciatura e a seus estudantes, futuros professores/as. Por meio das quais são redefinidos os princípios de reelaboração dos cursos de licenciatura que passaram a ter pressupostos como: o ensino visando à aprendizagem do aluno; o acolhimento à diversidade; o exercício de atividades de enriquecimento cultural (BRASIL, 2002).

Cabe mencionar ainda o Decreto $\mathrm{n}$ 응 6.755, de 29 de janeiro de 2009 que institui a Política Nacional de Formação de Profissionais do Magistério da Educação Básica, ao passo que disciplina a atuação da Coordenação de Aperfeiçoamento de Pessoal de Nível Superior (CAPES) no fomento a programas de formação inicial e continuada. Essa política é implementada buscando atender demandas da educação pela formação de professores/as. Um dos aspectos que fundamentam essa política tem relação com as quedas na procura pelas licenciaturas registradas desde a década de1990, pelos mais diversos motivos, como a baixa remuneração e as más condições de trabaIho aos professores/as.

Nesse contexto, o amparo à Formação de Professores/as para EJA se encontra no inciso VII do art. 4ㅇ da LDBEN 9394/96, em que está estabelecida a necessidade de atenção e respeito às características específicas dos trabalhadores matriculados nos cursos noturnos. Parece então clara a necessidade da exigência de formação específica para docência na EJA, conforme expõe o Parecer CEB/CNE 11/2000: "[...] trata-se de uma formação em vista de uma relação pedagógica com sujeitos, trabalhadores ou não, com marcadas experiências vitais que não podem ser ignoradas" (BRASIL, 2000, p. 58).

Além disso, o referido Parecer que institui as Diretrizes Curriculares Nacionais da EJA chama atenção para o vínculo que se estabelece na relação entre estudantes e professores/as, este é determinante para evitar a evasão e manter a permanência na EJA, assim como para os processos de ensino-aprendizagem. Portanto, se compreende que na EJA o respeito à opinião, à trajetória de vida, à cultura e aos saberes dos sujeitos estudantes, não só os mantém nos espaços educativos, mas possibilita a continuidade do processo de escolarização.

É importante destacar que embora existam políticas que revelem ordenamentos jurídicos que assegurem ou reconheçam a importância da formação de professores/as para a EJA, se percebem poucas iniciativas que dão conta de articular tais dispositivos ao que se vivencia nas redes de ensino e nos espaços de escolarização nessa modalidade.

Ao tomar como referência para essa dis- 
cussão os elementos político-legais, considera-se importante ampliar nossas compreensões sobre o processo de formação ou produção dos professores/as da EJA, no sentido de pensar possibilidades para um processo de formação não universalizado e que possam dar conta da diversidade de oferta da modalidade no campo da educação. Pois, ao assegurar garantias em termos de formação observa-se que as políticas em geral, quase sempre, definem padronizações para unificar tais processos formativos.

Os processos de formação de professores/as, numa perspectiva de produção do/a professor/a, poderiam ser pensados a partir de questões que nos permitam conhecer/compreender: quem são esses profissionais inseridos no campo da EJA? O que os levou a escolher a EJA como espaço de trabalho? Como os/as professores/as da EJA compreendem seu trabalho pedagógico? Quais representações possuem de seu próprio trabalho? Como reconhecem os espaços onde estão inseridos? Quais relações constituem com os profissionais que trabalham e com os estudantes da EJA? Como esses elementos se revelam nas práticas dos professores/as e nas imagens que produzem de si?

Parte dessas questões exige compreender a dimensão profissional e a formação de professores/as considerando as experiências, os acontecimentos, os diálogos tecidos com os pares e, além disso, aspectos pessoais - anseios, expectativas, crenças, representações, relações interativas - e dos próprios "modos de ser e estar na profissão, na sala de aula [...], pois faz falta integrar estas dimensões no quotidiano da profissão docente", fazendo com que elas sejam parte essencial de cada um/a como professor/a (NÓVOA, 1999, p. 11).
A partir dessa abordagem, buscou-se estabelecer relações com alguns teóricos no campo da filosofia contemporânea na intenção de pensar elementos da formação de professores/as que contribuam com um processo de produção de subjetividades, a partir do par conceitual experiência e transformação.

\section{EDUCAÇÃO X FORMAÇÃO OU PRODU- ÇÃO DE PROFESSORES/AS: (im) possibili- dade de experiência na relação com 0 mundo}

Nesse exercício de refletir sobre a formação de professores/as precisamos pensar que ela se articula a um projeto de educação da modernidade. A este respeito Agamben (2008), Benjamin (1994, 2000, 2009) e Larrosa $(1994,2002)$ discutem sobre a impossibilidade de se realizar experiência diante de um modo de viver normatizado/normalizado pela racionalidade científica imposta pela sociedade moderna. Há uma espécie de destruição da possibilidade de experiência e isso se demonstra pela própria vida do homem moderno, uma vida ao mesmo tempo individualizada, massificada, na qual os sujeitos não se afetam mais pelas relações com os outros, com os espaços ou com seu próprio trabalho.

Essas mudanças também estão vinculadas na modernidade às relações que se estabelecem com o tempo, pois este passa a ser cronometrado, assim como os espaços tornam-se esquadrinhados de forma a impor uma configuração da vida que tem por base a disciplina, o controle e a formatação do corpo. Para assegurar a legitimidade desse modo de produção de vida, as verdades se consolidam na modernidade como representações do real, um único real que 
pode (ilusoriamente) ser apreendido e ao mesmo tempo representado pela linguagem.

Nesse contexto, o sujeito passa a ter uma relação instrumental (alienada) com a palavra e com o próprio conhecimento. Essa concepção burguesa/representacional da linguagem para Benjamin (1994) impede a experiência, a criação e a expressão. Para ele a linguagem precisa ser compreendida como produção do mundo, pois a produção de si se dá linguisticamente. A linguagem não é o retrato do real em si e não pode apreender inteiramente o mundo no intuito de representá-lo.

A partir da compreensão entre a linguagem e as relações na vida moderna, Benjamin (1994) e Larrosa (2002), destacam como se desenvolvem os fluxos de informações e os seus reflexos no cotidiano das pessoas, dinâmica que perpassa os contextos escolares e de formação docente. As informações na modernidade se ampliam em termos de volume e acesso, e estão por toda a parte, mas já não carregam mais as marcas de quem as produz. Como tudo pode ser previsivelmente controlado, verificado e diagnosticado. O poder da ciência moderna ajuda a fortalecer discursos de verdade criados pelas próprias informações.

Além disso, o projeto moderno pressupõe que o sujeito possua uma essência, a de cidadão com direitos, pois todos agora são iguais perante a lei e por meio de aparatos jurídicos todos/as terão seus direitos assegurados. É preciso refletir sobre como essas noções implicam um projeto de educação, de escola ou formação de professores/as.

Em O governo de si e dos outros, obra que contempla uma análise dos elementos que compõem a democracia grega, Fou- cault (2010) chama a atenção para a diferença entre legalidade e legitimidade. Para ele a relação jurídica não dá conta de regrar relações humanas, pois só a palavra verdadeira e a política poderiam, numa perspectiva democrática, "orientar essas relações a partir do tripé parresía, isegoria e isonomia" (FOUCAULT, 2010, p. 147), ou seja, a experiência da política e da democracia só se daria a partir também de exercícios de relação de poder.

Portanto, para o teórico o ordenamento jurídico (que nada garante) e a prática política são complementares e não ocorrem em decorrência de um ou de outro, isso significa: somos fruto do que fazemos e do presente em que vivemos. Isso contradiz a noção contemporânea de que o bom cidadão se adapta ou cumpre normas, nessa linha para Foucault (2010) toda prática de poder comporta uma possibilidade de resistência. Isso auxilia a pensar na possibilidade de um processo de produção de professores/as que coloque sob análise as imposições/regula-mentações sobre seu próprio trabalho.

Tal compreensão nos exige pensar a educação e a própria produção de professores/as num projeto maior de formação humana, reconhecendo seu caráter provisório, imprevisível e de convívio com a incerteza. Refletir sobre as possibilidades de produção dos professores/as requer pensar o mundo, as relações, os direitos e a normatividade numa perspectiva de contingências e da imanência rompendo com a noção de essência, por isso nessa compreensão, que se contrapõe ao projeto moderno de educação, o mundo e a norma precisam se constituir como produções permanentes.

Como destaca Larrosa (2002) a vida humana sempre tem um resto, algo à margem 
que não pode ser controlado e aí se encontra um desafio: positivar ou não esse resto. A formação do sujeito na escola moderna se pauta pela lógica do assujeitamento, contudo "a produção das subjetividades pode se dar na produção de si com liberdade, há nesse caso uma ambivalência no conceito de governo de si - e dos outros em que o poder se constitui como dispositivo relacional e não vertical" (LARROSA, 1994, p.39).

Nesse contexto, pode contribuir a retomada de um dos conceitos trabalhados por Foucault $(2004,2010,2011)$ - o cuidado de si - que significa cuidar tanto do corpo quanto da alma, principalmente da alma como essência e algo ativo no indivíduo, o cuidado de si implica num conjunto de práticas sistemáticas.

A verdade moderna só prevê conhecer o mundo de modo objetivo, mas isso pouco diz sobre o que somos, na medida em que o sujeito surge como produto da disciplina, construído a partir de técnicas de individualização e procedimentos de totalização, que repercutem no apagamento de qualquer vestígio de subjetividade na produção do humano. Por isso o cuidado de si se refere à abertura da alma para o outro (saber ouvir), assim, nessa relação, o outro passa a fazer parte de mim, pois do outro é tomado o que é importante para se viver.

Pensar o cuidado de si e do outro ajuda a pensar sobre o projeto hegemônico de educação da modernidade, principalmente a partir das instituições escolares, suas dinâmicas e da formação para docência.

Essa discussão permite retomar a desconstrução, com base nos escritos de Benjamin (2009) e Agamben (2008), da noção de que a velha geração apresenta o mundo aos mais jovens, e assim, repassa também sua experiência, desencorajando as gerações mais jovens de fazerem suas próprias experiências. Essa ideia, de que as gerações mais velhas carregam o valor/peso da tradição e por isso detém certa autoridade, para os autores poderia significar a morte do movimento tradição/com-servação versus quebra/ruptura, como também da experiência enquanto dimensão constitutiva do homem conferindo falta de sentido à própria vida.

Entretanto, o cuidado de si pode ajudar a tecer não mais uma relação sem vínculo entre quem fala e quem ouve, na qual quem fala (professor/a ou formador/a de professor/a) fala de um saber do mundo para que o outro (aluno/a ou professor/a em formação) aprenda. Nesse sentido, aproximações a uma produção de professores/as, a partir do binômio experiência/transformação, se distancia dessa lógica ao passo que se desenvolve numa perspectiva formativa em que aquele que fala, fala de si e nesse movimento ajuda o outro a conhecer a si.

Como expõe Foucault (2010), para que alguém aprenda a cuidar de si há uma relação assimétrica, ninguém nasce pronto, pois nos constituímos no processo de produção de si. No entanto, essa relação só se consolida se houver a permissão do outro, em que ele se produz como sujeito singular, por isso essa compreensão traz um outro modo de produção das relações humanas. Cabe questionar quais articulações pode-se fazer sobre as relações entre os sujeitos inseridos no contexto escolar, e, principalmente como as formações de professores/as trabalham o cuidado de si e do outro ao pensar relações entre professores/asprofesso res/as, estudantes-estudantes, professores/as-estudantes (entre outras)? 
Para Foucault (2004) esse movimento de retorno a si não é individualista, pois "é preciso durante toda a vida, voltar os olhos, a atenção, o espírito, o ser por inteiro enfim, na direção de nós mesmos" (FOUCAULT, 2004, p. 254), ou ainda, "o movimento a ser feito há de ser então o de retornar a este centro de si para nele imobilizar-se", o que vai levar à "converter-se a si, a fazer a volta em direção a si mesmo" (FOUCAULT, 2004, p. 255). Aqui a conversão aparece como possibilidade de resistência, como algo que está sempre sendo produzido, uma prática permanente sobre si mesmo que também se revela como exercício de liberdade. O sujeito livre que cuida de si estabelece relações horizontais com os outros e nessa relação afeta e é afetado pelo outro. Foucault (2004) critica, portanto, a essencialização do sujeito e a busca externa como única possibilidade da produção de si, a ele interessa compreender como ao longo da história se produziram diferentes modos de subjetivação que na modernidade estão marcados pelo assujeitamento.

Nesse sentido, a escola e os espaços de produções de professores/as podem surgir como lugar de reinvenção permanente, rompendo com o que se apresenta na história da educação em relação às promessas eternamente não cumpridas da modernidade, tecendo modos de fazer que transformem as impotências em potências.

\section{NO VIÉS DE UMA CONCLUSÃO: a experi- ência e a transformação na formação ou na produção de professores/as}

O/a professor/a tem sido entendido como gestor/a, facilitador/a, comunicador/a ou até animador/a da aprendizagem, nesse sentido, seu papel e seu próprio processo de formação se definem numa perspectiva unilateral. O/a professor/a é quem faz o/a aluno/a aprender a partir de procedimentos, técnicas e estratégias previamente definidas. Nessa lógica só existe trabalho sobre a aprendizagem, isso acaba com elementos ligados ao ensino.

Logo, o foco está no que se deve ensinar (pré-definido antemão) e como ensinar, o que leva a uma negligência de questões maiores em relação ao projeto de formação humana (reconhecimento dos sujeitos) e a educação. Diante disso, cabe indagar: os/as professores/as possuem como obrigação fazer com que todos/as aprendam? E para isso, simplificamos o que ensinamos? Faz sentido que o/a professor/a facilite a aprendizagem para a autonomia? É possível pensar num processo educativo que afete aos professores/as e demais sujeitos inseridos nos contextos escolares? Ou ainda, é possível pensar na produção de professores/as nessa relação entre experiência e transformação?

Essa discussão envolve questionar também o papel da escola, ou melhor, o papel da escola como possibilidade de realizar experiência. O/a professor/a tem experiência na/da escola? A experiência se apresenta como possibilidade de produção do/a professor/a?

Nóvoa (1995) apresenta reflexões nesse sentido e busca entender algumas dessas questões a partir das seguintes articulações: o desenvolvimento pessoal - a partir da produção da vida do/a professor/a, o desenvolvimento profissional - com base na produção da profissão docente - e o desenvolvimento organizacional/institu-cional tendo por referência a produção da escola.

Portanto, torna-se importante estar atento às práticas pedagógicas em que se 
estabelecem, regulam e modificam as relações do sujeito consigo mesmo e nas quais se constitui a experiência de si, como escreve Larrosa (2002). Mas como seria possível no âmbito das instituições formadoras pensar na produção do/a professor/a como aquele/a que produz o texto e nisso produz a si mesmo ou produz transformações sobre si?

Mediante essa questão se faz importante pensar de modo mais cuidadoso sobre as políticas de auto narração - presentes também nas formações de professores/as, que como forma de produção de possibilidade de fazer experiência precisam partir de uma compreensão na qual o poder atravessa o discurso, pois as práticas discursivas nas quais se produzem e medeiam histórias pessoais não são autônomas, estão incluídas em dispositivos sociais e normativos, por isso "também são práticas sociais organizadas e constituídas em relações de desigualdade, poder e controle" (LARROSA, 1994, p. 71). Como salienta Larrosa (2002) é preciso refletir a respeito disso, tendo em vista os poderes que aí gravitam, ou mesmo, os lugares nos quais o sujeito é induzido a interpretar-se a si mesmo, a constituir as regras do discurso que lhe dão identidade impondo uma direção. Assim a subjetividade dos/as professores/as em formação pode se construir também por meio da imposição de certos padrões de auto narração.

Para Larrosa (1994, p. 57) "tomar os dispositivos pedagógicos como constitutivos da subjetividade é adotar um ponto de vista pragmático sobre a experiência de si", entretanto reconhecer a contingência e historicidade desses mesmos dispositivos é adotar um ponto de vista genealógico. Portanto, a noção de pedagogia em Larrosa (2002) pode ajudar a pensar sobre a produção de professores/as como experiências de si nas quais esses indivíduos podem se tornar sujeitos de um modo particular.

Todavia, a experiência de si no trabalho com narrativas pessoais ou histórias de vida não está necessariamente dirigida à tomada de consciência, porque será em seu interior, com suas regras e no modo de sua realização, que a tomada de consciência como transformação da experiência de si será normativamente e praticamente produzida. Nesse sentido, para Larrosa (1994, p. 59) torna-se fundamental, ao pensar a relação entre a experiência de si e os dispositivos pedagógicos, analisar a "produção de experiência de si (autoconhecimento, tomada de consciência ou autorreflexão crítica) no interior de um dispositivo (práticas pedagógicas com regras e determinadas formas de realização)".

Na dimensão do autoconhecimento cabe salientar que ao ver-se, expressar-se, narrar-se (sentido dado ao que acontece) ou julgar-se, mesmo que exista um forte condicionamento para que o sujeito se veja/expresse/narre/ julgue de determinadas formas, ele/a participa, intervém nesses atos, não está totalmente determinado nessa lógica, o que permite alguma possibilidade de experiência/transformação no processo de produção de professores/as.

Nesse sentido, é preciso pensar outra pedagogia que tenha a produção de si como horizonte, ou seja, a saída poderia estar nas relações, na produção de si e na materialização do discurso, pois "o que determina um olhar tem uma origem, depende de certas condições e práticas de possibilidade" e como todo contingente pode sofrer transformações, pode ser visto de outro modo, possibilita ensaiar novas formas de subjeti- 
vação e produção de singularidade ou nas palavras de Larrosa (1994, p. 84)

Ver-se de outro modo, dizer-se de outra maneira, julgar-se diferentemente, atuar sobre si mesmo de outra forma, não é outra forma de dizer "viver" ou "viver-se" de outro modo, "ser outro"? E não é uma luta indefinida e constante para sermos diferentes do que somos o que constitui o infinito trabalho da finitude humana, e nela, da crítica e da liberdade?

A formação de professores/as para atuação na Educação Básica ocorre de modo considerado generalista, sem levar em conta todas as especificidades que demandam os níveis e modalidades educacionais. Diante disso, para atuação na Educação de Jovens e Adultos (EJA) os professores/as recebem, quase sempre, uma formação continuada em serviço. A EJA nesse contexto formativo é apresentada/discutida como modalidade que precisa romper, de algum modo, com as lógicas estruturantes da escolarização (dita) regular de idade obrigatória, no intuito de não reproduzir mecanismos que levaram esses sujeitos a desistirem da escola em outros tempos de suas vidas por dificuldades de acesso/permanência ou por conta da rigidez/inflexibilidade de algumas propostas pedagógicas e dinâmicas curriculares. Essa concepção impõe grandes desafios para pensarmos um processo de formação continuada de professores/as para a EJA que irrompa com a própria racionalidade da formação inicial recebida para a docência no Ensino Superior e com a formação do professor constituída a partir de seu trabalho no contexto escolar.

Nóvoa (1999) sugere, como alternativas de formação continuada às abordagens au- tobiográficas (não apenas num sentido pessoal, mas geracional), as práticas de escrita pessoal e coletiva, o desenvolvimento de competências dramáticas e relacionais, bem como o estímulo a uma atitude investigativa em relação à educação, escola e os elementos que tecem as práticas pedagógicas.

Isso significa, também a partir do par conceitual apresentado - experiência e transformação - que há uma impossibilidade de separar o/a professor/a da pessoa que ele é. Tendo essa compreensão é fundamental pensar num processo de produção de professores/as, nesse caso para a EJA, que se articule a um projeto maior de formação humana, para além da própria história da constituição cultural e política do sistema educacional brasileiro. Nesse sentido, convém realizar um exercício reflexivo que nos possibilite questionar/pensar outras possibilidades de produção subjetiva dos/as professores/as.

Mediante a essa perspectiva, a produção de professores/as precisa ter como referencial um mundo ambivalente, cuja proposição de normatividades para a contingência parta de quem vive. Isso exige rever no próprio processo educativo, as relações que se tecem com elementos como: tempo, espaço, corpo, linguagem e técnica.

Assim, torna-se possível pensar a produção de professores/as da EJA numa escola não cronometrada, sem tanta intencionalidade racional, com a compreensão de que a linguagem não comunica conteúdo, mas comunica a comunicabilidade e que permita relações com o corpo, com o fazer experiência para transformações.

Diante disso, convém questionar: é possível pensar numa produção de professores/as enquanto formação/educação humana? Numa escola que lide com o tempo 
presente? Com os sujeitos que hoje estão na escola? Talvez seja viável, ao se tomar a concepção de tempo em Benjamin (2000), como aquele que permite a redenção do ocorrido no passado rememorado, abrindo possibilidades para um novo tempo, pois a crítica ao cenário atual só pode se dar diante de nossa própria inserção nesse presente.

\section{REFERÊNCIAS}

AGAMBEN, G. Infância e história - Ensaio sobre a destruição da Experiência. In AGAMBEN, G. Infância e história. Belo Horizonte: UFMG, 2008. p. 07-91.

ARROYO, M. G. Educação de jovens e adultos: um campo de direitos e de responsabilidade pública. In: SOARES, L. (Org.). Diálogos na educação de jovens e adultos. São Paulo: Autêntica, 2005. P. 19-50.

BENITE, A. M. C.; et al. Trajetória da escolarização de jovens e adultos no Brasil: de plataformas de governo a propostas pedagógicas esvaziadas. Revista Ensaio: avaliação, políticas públicas e educação. Rio de Janeiro, v. 18 , n. 67 , p. 389-410, abr./jun. 2010.

BENJAMIN, W. Experiência e pobreza. Magia e técnica, arte e política: ensaios sobre a literatura e a história da cultura. São Paulo: Brasiliense, 1994. P. 114-119.

. Sobre alguns temas de Baudelaire. In: BENJAMIN, W. A modernidade e os modernos. Rio de Janeiro: Tempo Universitário, 2000. P. 37-77.

Experiência. In: BENJAMIN, W. Reflexões sobre a criança, o brinquedo e a educação. São Paulo: Duas Cidades/Ed. 34, 2009. P.21-26.

BRASIL. Parecer CNE/CEB 11/2000, que dispõe sobre as diretrizes curriculares para a
Educação de Jovens e Adultos. Brasília, DF: MEC/ CNE, 2000.

. Lei n. 9.394, de 20 de dezembro de 1996. Estabelece as diretrizes e bases da educação nacional. Disponível em: <http:// www.planalto.gov.br/ccivil03/leis/19394.ht m>. Acesso em: 20 out. 2016.

- Conselho Nacional de Educação. Câmara de Educação Básica. Institui Diretrizes Curriculares Nacionais para a Formação de Professores/as da Educação Básica, em nível superior, curso de licenciatura, de graduação plena. Resolução CNE/CP no 1 de 18 de fevereiro de 2002. Disponível em: <http://portal.mec.gov.br/cne/arquivos/pdf /rcp01_02.pdf>. Acesso em: 10 mar. 2016. FOUCAULT, M. A hermenêutica do sujeito. São Paulo: Martins Fontes, 2004.

- O governo de si e dos outros. São Paulo: Martins Fontes, 2010.

A coragem da verdade. São Paulo: Martins Fontes, 2011.

HADDAD, S. (Coord.). Ensino supletivo no Brasil: o estado da arte. Brasília, DF: REDUC, 1987.

. Educação de jovens e adultos no Brasil (1986-1998). Brasília, DF: MEC/INEP/ COMPED, 2002.

HADDAD, S.; DI PIERRO, M. C. Escolarização de jovens e adultos. Revista Brasileira de Educação, São Paulo, n. 14, p. 108-130, 2000.

LARROSA, J. Tecnologias do eu e educação. In: SILVA, T. T. da (Org.). O sujeito e a educação. Petrópolis: Vozes, 1994.

Notas sobre a experiência e o saber de experiência. Rio de Janeiro. Revista Brasileira de Educação, São Paulo, n. 19, p. 2028, 2002.

NÓVOA, A. Profissão professor. Porto: Porto Editora, 1995.

\section{. A "nova" centralidade dos professo-}


res/as: do excesso dos discursos à pobreza das práticas. Lisboa: Repositório da Universidade de Lisboa, 1999. Disponível em: <ht tp://repositorio.ul.pt/handle/10451/684>.

Acesso em: 19 mai. 2016.

SARTORI, A. A Legislação Educacional e as Concepções de EJA. In: LAFFIN, M. H. L. F. (Org). Educação de Jovens e Adultos na Diversidade. Livro 02. NUP, UFSC, 2010. p. 76-94.

- Legislação, políticas públicas e concepção de Educação de Jovens e Adultos. In: In LAFFIN, M. H. L. F. (Org). Educação de Jovens e Adultos e Educação na Diversidade. NUP, UFSC, 2011. p. 14-124.

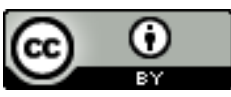

License information: This is an openaccess article distributed under the terms of the Creative Commons Attribution License, which permits unrestricted use, distribution, and reproduction in any medium, provided the original work is properly cited.

Artigo recebido em 09 de maio de 2017.

Avaliado em 02 de setembro de 2017.

Aceito em 18 de setembro de 2017.

Publicado em 22 de setembro de 2017.

\section{Como citar este artigo (ABNT):}

CABRAL, Paula; VIGANO, Samira de Moraes Maia. Formação ou produção de professores/as para a educação de jovens e adultos?. Estação Científica (UNIFAP), Macapá, v. 7, n. 2, p. 21-31, maio/ago. 2017. 